$6 \mid \mathrm{R}$ es e NHAS 


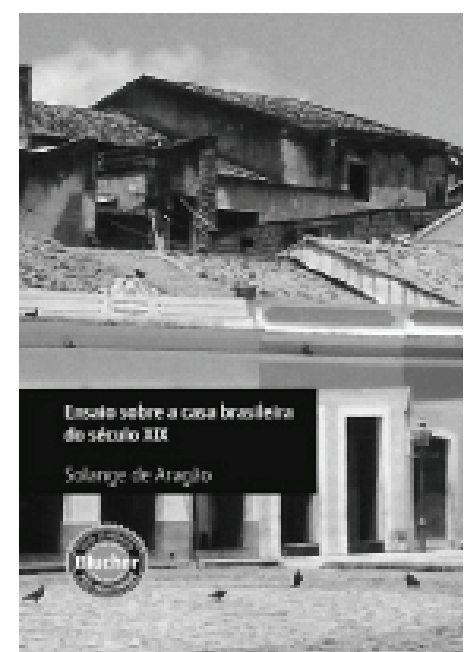

ENSAIO SOBRE A CASA

BRASILEIRA DO SÉCULO XIX

aragão, Solange de. São Paulo: Selo

Acadêmico Blucher - Pós-Doutorado, 2OII, P. 302

ISBN: $978-85-8039-057-5$

Carlos A. C. Lemos

\section{UM ENSAIO À ESPERA DE OUTRO}

Esse livro, que resulta das pesquisas da arquiteta Solange de Aragão em seu pós-doutoramento, é um raro exemplo de exaustão de um tema. Nele, a autora analisa em profundidade todo o pensamento de Gilberto Freyre a respeito da casa brasileira. Põe às claras tudo o que o celebrado historiador da sociedade pernambucana, ou sociólogo do patriarcalismo do Nordeste, considerava a respeito dos "lugares de morar". Todos sabem, no entanto, que aquele autor cometeu alguns enganos ou omissões, quando tratava das questões arquitetônicas dos povos do Sudeste e Sul do Brasil, sobretudo do mundo mameluco de Piratininga, principalmente na ocasião em que se refere a programas de necessidades ou técnicas construtivas. Entretanto, quando se restringe a seu meio social canavieiro, é insuperável. Daí meu conselho de há tempos à autora (p. 14), no intuito de conhecer melhor esses méritos regionalistas de Gilberto Freyre, porque suas elucubrações a respeito do ato de morar poderiam, até certo ponto, ser generalizadas, tendo-se em vista o cenário brasileiro.

E, assim, Solange de Aragão se saiu muito bem na parte final do livro, quando se baseia em estudo fenomenológico de Gaston Bachelard, sobre a casa e os significados que podem assumir cada uma das dependências de uma construção residencial, mesmo tentando considerar como "exemplo brasileiro" um sobrado genuinamente recifense.

Talvez por olhar a obra de Gilberto Freyre com outros olhos, quem sabe, menos benevolentes e mais cansados que os da autora, considero-me apto a fazer alguns comentários a esse "ensaio sobre a casa brasileira do século XIX". Repito, essa expressão "casa brasileira", sem maiores adjetivações, exige sejam igualmente abordados exemplares do País todo, de Norte a Sul, porque o Brasil 
sempre foi um arquipélago de ilhas culturais, cada qual com sua história e peculiaridades, no atendimento às condições climáticas, aos recursos ambientais, às disponibilidades econômicas, ao "saber fazer" dos habitantes, etc. Muitas vezes, certas generalizações são impossíveis, quando pensamos o Brasil como um todo. A bem dizer, nosso sociólogo levou a sério a frase do engenheiro francês Louis Léger Vauthier, em meados do século 19, em Recife, ao dizer que "quem viu uma casa brasileira, viu todas". Isso é uma meia verdade, porque, de um modo ou outro, as feições e modinaturas nos vieram de Portugal e aqui seguidas, na maioria das vezes, por meio de posturas ditadas tanto pela tradição como pelas câmaras municipais, desejosas de ver suas cidades "harmoniosas", especialmente após os trabalhos de reconstrução de Lisboa, em 1755, cujos méritos estéticos vieram para cá, transportados pelos engenheiros militares, profissionais eficientes, em sua atuação no auxílio à população. Se, dentre as várias técnicas construtivas, os edifícios se assemelham, em seus âmagos, no entanto, acolhendo diversos programas de necessidades, conforme a região, podem se diferenciar bastante. Por isso, caberia melhor, no título desse livro, a expressão "casa pernambucana" ou "nordestina".

É fato que Gilberto Freyre abusou nas generalizações, fazendo chegar ao Sul do Brasil suas constatações, incluindo, em seu universo residencial, por exemplo, o sobrado açoriano de Santa Catarina e Rio Grande do Sul. No entanto, nunca houve, na região colonizada pelos ilhéus, uma arquitetura que lembrasse os Açores. Naquelas ilhas, o clima é realmente áspero, ventoso e frio, e lá o centro de interesse da casa, térrea ou assobradada, é forçosamente o fogão, com sua chaminé. Aqui, aqueles colonos, chegados em meados do século 18, simplesmente copiaram a casa popular litorânea tradicional, de pedra entaipada, preexistente em Cananeia, Iguape, Itanhaém, Santos e Ubatuba, todas, naquela época, destituídas de fogão fixo de alvenaria, pois o clima quente claramente sugeria as lides culinárias espalhadas fora do interior da moradia. A influência açoriana fixou-se apenas em alguns cardápios, em certas manifestações religiosas e no sotaque cantado, quase musical, daqueles patrícios do Rio Grande do Sul e de Santa Catarina.

Quanto aos azulejos nas fachadas dos sobrados brasileiros, também há desinformações endossadas por Solange Aragão. Não há dúvidas, as primeiras forrações de frontispícios de sobrados deram-se em São Luís do Maranhão, motivadas pela permanente infestação de fungos nas argamassas de revestimento, causada pela alta higroscopia, devida à cal impura, feita a partir da trituração de moluscos do fundo do mar, cal com alta porcentagem de cloretos. Essa providência, garantidora do bom aspecto das fachadas, tornou-se moda e, inclusive, chegou a Lisboa, como novidade em paredes externas, e, de lá, exportada para Recife, Salvador e Rio, já em pleno século 19.

Ainda quanto aos sobrados magros do Recife, também é oportuna uma referência ao ensaio de antropólogo português Ernesto Veiga de Oliveira, "Casas esguias do Porto e sobrados do Recife", apresentado em um dos Colóquios LusoBrasileiros e publicado no Recife, em 1986, pela Pool Editorial, obra que não consta da bibliografia deste livro. Ali é posta em seu devido lugar a pretensa contribuição holandesa à arquitetura urbana recifense. Daqueles invasores, restaram mesmo, sem dúvida, apenas suas fortificações. 
Cremos que Solange de Aragão tenha se distraído, ao intitular seu livro. Apenas trocou um no por um do, já sabendo que dificilmente iria, em suas pesquisas, isolar e analisar unicamente casas projetadas e construídas após o ano de 1801, sobretudo nas 34 páginas do capítulo 5, "A casa brasileira na pintura paisagística, na fotografia de paisagens e nos desenhos dos viajantes". Nas paisagens de Ender, por exemplo, executadas a partir de 1817, tanto nas cariocas como nas de São Paulo, todo o casario mostra construções do século 18, conforme assinala Gilberto Ferrez (p. 178). Tanto as referências e opiniões de viajantes, como temas urbanos dos fotógrafos, e tal qual os anúncios de jornal, nada dizem com clareza sobre épocas, ficando o leitor sem saber se as casas ali mencionadas são efetivamente do século 19.

E, finalmente, gostaríamos muito de saber por que motivo este ensaio não é ilustrado, para que houvesse a possibilidade de um contraponto entre as construções coloniais, que, por sinal, ainda continuaram a ser levantadas durante o primeiro quartel do século 19 , e as construções ecléticas, propriamente ditas, principalmente as historicistas, verdadeiras marcas do século 19, cujos programas e partidos arquitetônicos, vindos de novas técnicas construtivas, representavam a modernidade europeia chegada a nosso Império. No tempo colonial, cada região brasileira tinha sua técnica construtiva tradicional, assumindo uma vernaculidade em que as variações eram meramente quantitativas. Expliquemos: nas cidades, tanto as casas ricas como as mais humildes dos arrabaldes eram levantadas com os mesmos materiais, cobertas com as mesmas telhas, pintadas com a mesma cal branca. A única diferença estava no número de cômodos. Com a chegada do ecletismo, os variados estilos exigiam novo e caro material de construção. Em São Paulo, por exemplo, a tricentenária taipa de pilão, de todas as casas, foi substituída pela alvenaria de tijolos. As telhas de capa e canal, pelas telhas planas, ditas "de Marselha", ou pelas placas de ardósia. Grandes vidros jateados nas janelas, em lugar das treliças. E, o principal, começou-se a morar à moda francesa, com o vestíbulo dirigindo os passos, entre as três zonas previstas pela rigidez do novo programa: a de receber e estar, a de repousar e a de serviço. Agora, a diferença entre a casa rica, o palacete ou o sobrado brasonado do barão do café ou rico usineiro nordestino, e a casa do pobre, ou do modesto lar da classe média, passou a ser também qualitativa. Não só quanto à construção propriamente dita, mas quanto ao passadio; o pobre jantava à luz de velas ou candeias; o remediado degustava a carne assada iluminado pelo lampião belga, abastecido de querosene; e o rico ceava o cardápio francês, à luz viva do gás acetileno, produzido no quartinho do quintal, ao lado da cavalariça. A meu ver, esse segundo modo de viver, na época do ecletismo, não foi examinado em sua inteireza, em Manaus e Belém, cidades da borracha; em Recife e Salvador, dos engenhos de açúcar; no Rio de Janeiro, a capital do País; em São Paulo, que, de repente, passou da pobreza à extrema riqueza, de caipira a cosmopolita; que, em 40 anos, de 1860 a 1900, passou de 25 mil habitantes a 243 mil pessoas, de falas e sotaques os mais variados. Sem dúvida, no caso, o contraponto acima alvitrado é fundamental.

Certamente, naquelas capitais atrás arroladas, fossem os estilos os mesmos, os sobrados e palacetes teriam, no entanto, diferentes ambientações, diante de vários climas, variados volumes ou diversos partidos arquitetônicos, e, quem sabe, 
estariam sugerindo também distintas sistematizações das abstrações insinuadas na fenomenologia de Bachelard e, por que não, nas de Gilberto Freyre. Daí a pertinência da hipotética troca do título dessa obra, para Ensaio sobre a casa nordestina no século XIX.

Repito, esse livro é extremamente bem escrito e sua seriedade está implícita no rigor com que foi conduzida a pesquisa, em toda a obra de Gilberto Freyre, sobre 0 ato de morar no Nordeste. É um livro eminentemente didático, cujos méritos estão acima de minhas ressalvas, dirigidas a uma possível

complementaridade futura, talvez em um segundo volume, relativo ao resto do País.

\section{Carlos A. C. Lemos}

Professor titular do Departamento de História da Arquitetura e Estética do Projeto e do curso de Pós-Graduação da FAUUSP. É autor de vários livros, entre eles,

Alvenaria burguesa: breve história da arquitetura residencial de tijolos em São Paulo a partir do ciclo econômico liderado pelo café, Nobel, 1985; e Casa paulista: história das moradias anteriores ao ecletismo trazido pelo café, Edusp, 1999.

Rua Maranhão, 88. Higienópolis

01240-000 - São Paulo, SP

(11) 3017-3150

cpgfausec@usp.br 